\title{
ATIVIDADE LÚDICA E INTERDISCIPLINAR BASEADA EM JOGO DE TABULEIRO E CARTAS PARA A APRENDIZAGEM DE LÍNGUA, LITERATURA INGLESA E MATEMÁTICA NA EDUCAÇÃO BÁSICA
}

\author{
Gerson Bruno Forgiarini de Q̨uadros ${ }^{1}$
}

\begin{abstract}
RESUMO
A busca por atividades interdisciplinares e com propostas lúdicas de aprendizagem mobilizou professores e alunos para a criação de um jogo intitulado Clash of Class (Embate da Aula). Trata-se de um jogo de cartas e tabuleiro que possui uma dinâmica voltada ao desenvolvimento de operações matemáticas, leitura de imagens e textos instrucionais em inglês para a resolução dos desafios do game. 0 presente trabalho teve origem em um projeto de ensino interdisciplinar, envolvendo as áreas de linguagens (língua inglesa e artes), matemática e design gráfico. 0 objetivo do estudo foi investigar o modo como os alunos se engajaram na atividade do jogo, descrevendo os processos de resolução de desafios com o uso da matemática para vencer os embates. Os dados apurados por meio de entrevistas e observações de campo mostram que os aprendizes estavam motivados durante as propostas lúdicas do jogo por conta da dinâmica dos desafios. Por fim, entendemos que o trabalho colaborativo realizado no projeto e a integração do jogo como ferramenta auxiliar de ensino pode contribuir para aprimorar o processo educativo. Dessa forma, os jogadores não são apenas expectadores. Eles também são atores que propõem finais imprevisíveis para a sua aprendizagem.
\end{abstract}

PALAVRAS-CHAVE: Jogos de cartas e tabuleiro.

\section{ABSTRACT}

The search for interdisciplinary activities and with ludic proposals of learning has mobilized teachers and students for the creation of a game called Clash of Class. It is a card-and-board game that has a dynamic approach to the development of mathematical operations, reading of images and instructional texts in English to solve the challenges of the game. The present work was originated in an interdisciplinary teaching project, involving the areas of languages (English language and arts), mathematics and graphic design. The objective of the study was to investigate how students engaged in the game activity, describing the processes of solving challenges with the use of mathematics to overcome the clashes. The data from interviews and field observations show that the learners were motivated during the playful proposals of the game because of the dynamics of the challenges. Finally, we understand that the collaborative work carried out in the project and the integration of the game as an auxiliary teaching tool can contribute to improve the educational process. That way, players are not just spectators. They are also actors who propose unpredictable endings for their good learning.

KEYWORDS: Card and board games.

\section{Introdução}

O desenvolvimento de propostas de ensino interdisciplinar com o uso de jogos pode potencializar 0 engajamento dos estudantes em resolução de atividades de desenvolvimento linguístico e problemas matemáticos, por exemplo. $E$, nesse sentido,

\footnotetext{
'Doutorado em Letras pela Universidade Católica de Pelotas, Brasil(2016) Professor Substituto do Instituto Federal de Educação, Ciência e Tecnologia de Mato Grosso do Sul, Brasil. Email: gerson.quadros@ifms.edu.br
} 
buscar um jogo que se encaixe numa atividade de aprendizagem não é uma tarefa fácil. Jogos educacionais nem sempre são motivadores, interessantes ou adequados para serem explorados em determinados conteúdos.

Então, a busca por atividades interdisciplinares e com propostas lúdicas de aprendizagem mobilizou professores e alunos para criação de um jogo educacional intitulado Clash of Class (Embate da Aula). Trata-se de um jogo de cartas e tabuleiro que possui uma dinâmica voltada ao desenvolvimento de operações matemáticas, leitura de imagens e textos instrucionais em língua inglesa para resolução de problemas/desafios.

O jogo foi inspirado em lendas e mitos da Idade Média, uma vez que os jogadores/estudantes duelam entre si em uma espécie de batalha medieval entre exércitos de cavalarianos, criaturas lendárias, bruxas e magos. A proposta pedagógica é que os alunos possam participar dos desafios do jogo de cartas e tabuleiro, contextualizando atividades que envolvam as habilidades linguísticas e matemáticas em uma proposta interdisciplinar.

Nesse sentido, o presente trabalho, que teve origem em um projeto de ensino interdisciplinar intitulado "Clash of Class: Gamificação no Ensino de Línguas" realizado no Instituto Federal de Educação, Ciência e Tecnologia de Mato Grosso do Sul, Campus Dourados. Este estudo envolveu as áreas de inglês, matemática e design gráfico e teve por objetivo investigar o modo como os alunos se engajaram na atividade do jogo, descrevendo os processos de resolução de desafios com a leitura e compreensão de texto instrucional em inglês e o uso de operações matemáticas para vencer os embates de cartas com personagens épicos da idade média da literatura inglesa.

O trabalho está estruturado nas seguintes seções: a primeira apresenta os procedimentos metodológicos adotados para o desenvolvimento da atividade de aprendizagem com a realização do estudo de caso e o desenvolvimento do protótipo do jogo. Os resultados obtidos a partir da coleta e análise dos dados são apresentados na seção 3. A seção 4 discorre sobre as considerações finais, relatando os resultados sobre o modo como as atividades experimentadas no jogo Clash of Class exerceram influências sobre os aspectos motivacionais e de aprendizagem dos sujeitos da pesquisa.

\section{Desenvolvimento da Atividade}


A atividade proposta é considerada de cunho qualitativo (BOGDAN; BIKLEN, 1994), porque adota um conjunto de métodos de investigação que foca nos aspectos subjetivos, buscando compreender as particularidades e experiências individuais dos sujeitos jogando Clash of Class. Este trabalho foi desenvolvido a partir um estudo de caso (YIN, 2001) com um grupo de 4 alunos com idades entre 15 e 16 anos, de ambos os sexos, no Instituto Federal de Educação, Ciência e Tecnologia de Mato Grosso do Sul, localizado na cidade de Dourados. Os sujeitos da pesquisa foram selecionados por meio de processo seletivo via sorteio, uma vez que vários manifestaram o interesse em participar do estudo. 0 projeto desenvolvido teve como foco a observação comportamental dos sujeitos durante os embates do Clash of Class.

\subsection{Etapas do Projeto}

O projeto Clash of Class teve duas etapas: a da prototipagem $e$ a de aplicação/testagem. Na etapa da prototipagem, os professores de inglês, matemática e de design gráfico, juntamente com a participação de dois alunos experientes em jogos de cartas desenvolveram um tabuleiro e um deck (coleção) com vinte e cinco cartas (Figura 1) por meio de programas de edição gráfica de forma a simular uma espécie de campo de batalha baseado nas lendas do Rei Arthur.
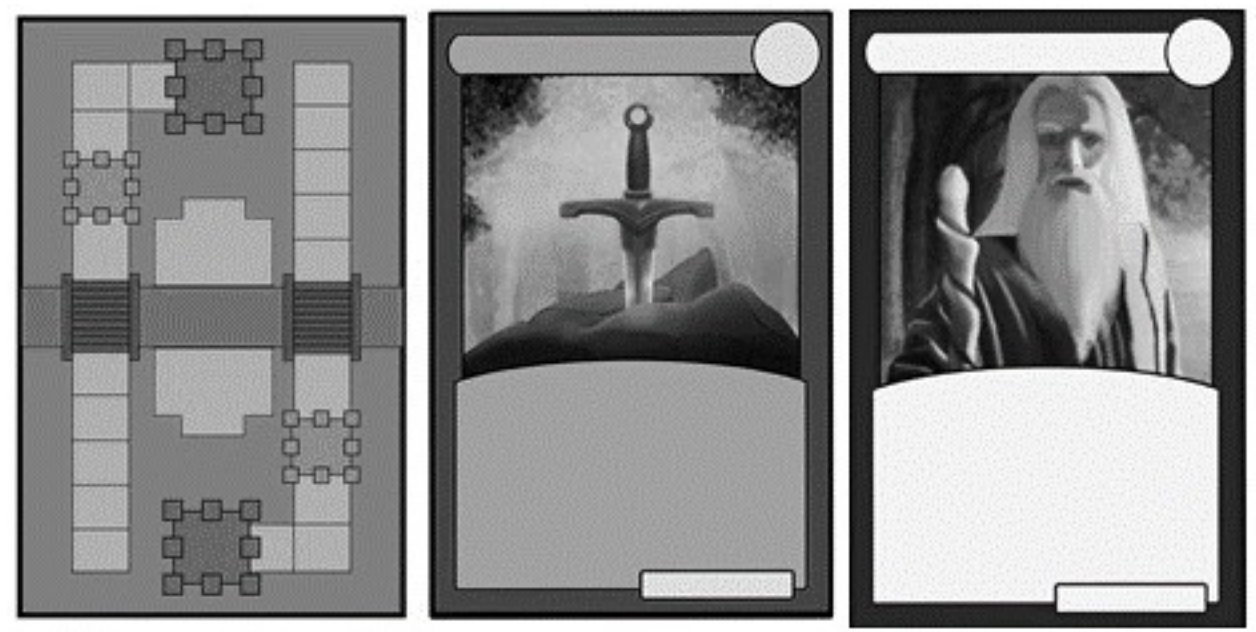

Figura 1. Prototipagem do deck de cartas e tabuleiro.

Fonte: $\mathrm{O}$ autor

Na etapa de aplicação, os sujeitos foram convidados a participar do jogo como uma proposta de aprendizagem envolvendo a compreensão de textos com instruções em inglês, 
e operações matemáticas cuja finalidade consistia em obter a melhor combinação de pontos de ataque e defesa. 0 vencedor era o jogador que obtivesse êxito em pelo menos dois de três embates.

\subsection{Instrumentos para a coleta e análise de dados}

Para a coleta de dados, foi utilizado um roteiro para a realização de uma entrevista semiestruturada com os aprendizes (Apêndice 1) para descrever o modo como se envolveram durante os embates do jogo. As entrevistas foram gravadas e transcritas, destacando as de maior relevância para este estudo. Complementarmente, foram feitas observações de campo pelo professor de inglês, na condição de autor-pesquisador, e registradas à mão em diário de bordo.

2.3 0 desenvolvimento da proposta educacional do jogo

Criar uma atividade que envolva diversão e aprendizagem é o anseio de todo o professor. 0 interesse em desenvolver um projeto interdisciplinar de modo lúdico nasceu a partir de um jogo de telefone celular conhecido por Clash Royale (Embate Real). Nesse jogo, a dinâmica envolve o uso do pensamento matemático para vencer o oponente. Cada jogador recebe cerca de 20 a 30 cartas durante 3 minutos de embate e as cartas têm poderes de ataque e defesa e a missão é derrubar o castelo adversário.

A partir desse jogo, pensou-se na possibilidade de se criar uma versão não digital. Para isso, seriam necessárias algumas adaptações. Buscou-se, então, sobre como materializar um jogo que pudesse explorar estratégias de leitura e aprendizagem de vocabulário em língua inglesa. Assim, nasceu a ideia do Clash of Class, originalmente pensado para ensino de língua e literatura inglesa. No entanto, com a possibilidade de criação de uma proposta pedagógica interdisciplinar, percebeu-se a potencialidade de se trabalhar com outras disciplinas, tais como artes, design gráfico, história e matemática.

O Clash of Class tem 25 cartas, organizadas em 4 categorias: a) Cavalarias; b) Criaturas lendárias; c) Bruxas, magos e feiticeiros; d) Artefatos mágicos. Essas cartas possuem textos descrevendo suas características e seus poderes de ataque e defesa contra os oponentes em cada embate. Cabe aqui ressaltar que, por meio de sorteio, os estudantes selecionados para a realização deste projeto realizado no IFMS Campus Dourados já 
possuíam experiência com jogos de cartas e, evidentemente, demonstraram interesse em seguir participando no desenvolvimento do protótipo depois da pesquisa para explorar e aplicar na educação básica.

A dinâmica do jogo foi desenvolvida pelo professor de inglês em conjunto com o de matemática, visando a jogabilidade a partir das operações matemáticas e interpretação textual das regras escritas em inglês com a temática de um clássico da literatura inglesa: The Arthur King. Em síntese, o jogo transcorre da seguinte maneira:

a) Cada jogador recebe 3 cartas;

b) Há o sorteio para quem inicia a partida;

c) cada jogador deve soltar uma carta ao lado do tabuleiro;

d) vence aquele que possuir cartas com maior valor (ataque e defesa) em uma disputa de "melhor de três descartes" em relação às do seu oponente. Essa disputa consiste em três descartes de cartas, uma vez para cada jogador. Na sequência de cada descarte, realiza-se a mensuração de forças de ataque e defesa (as cartas têm uma pontuação específica para cada personagem literário do jogo) para ver quem vence o embate em pelo menos duas de três rodadas.

e) A cada embate vencido, o jogador move o seu peão (The King - The Queen) em uma casa. O objetivo do jogo e fazer com que a peça móvel representando o "Rei" ou a "Rainha" sobre o tabuleiro avance onze casas para conquistar o castelo do oponente, consolidando a sua vitória no jogo.

\section{Resultados e Análises}

Os dados coletados junto aos participantes desta pesquisa foram transcritos $e$ organizados em categorias para melhor compreensão dos fenômenos observados a partir dos embates entre os oponentes durante a realização do jogo. Vale ressaltar que os sujeitos tiveram uma instrução inicial sobre as regras e dinâmicas do jogo e informações sobre as características de cada tipo e categoria de cartas, além da compreensão dos pontos de ataque e defesa para a dinâmica do jogo Clash of Class. 
O professor de inglês realizou as entrevistas, seguindo a ordem das questões de modo semiestruturado (Apêndice 1) e os sujeitos, assim, produziram suas respostas sobre a questão l:

Sujeito A: 0 jogo é interessante porque além da sorte você tem que combinar os valores das cartas pra saber se ganhou ou perdeu.

Sujeito B: É muito parecido com outros jogos de cartas. O interessante é que pode ter uma carta com menor poder e mesmo assim vence o teu adversário.

Nesse item de análise, os estudantes descrevem o modo como o jogo se torna interessante a partir da semelhança com outros jogos de cartas que previamente conheciam. $O$ sujeito $B$, nos destaca que o jogo se torna interessante por ser imprevisível, uma vez que ter a carta mais forte nem sempre possa significar que o embate está vencido. Esse fator pode ser um elemento desafiador que exige pensamento matemático sobre probabilidades, além de exigir o uso de estratégias e tomadas de decisão a cada descarte de uma carta.

Ainda sobre 0 item 1 do questionário, os sujeitos demonstraram uma boa aceitação do jogo e até informaram sobre seu conhecimento prévio a respeito desse tipo de carta. No item 2, os informantes relataram já conhecer jogos de cartas ao estilo batalhas medievais. Sobre a aprendizagem com o Clash of Class, destacada na questão 3, os sujeitos assim responderam:

Sujeito A: É possível sim aprender porque tem que pensar bastante antes de largar a carta na mesa e ver a combinação com as cartas mágicas.

Sujeito C: O jogo é uma boa estratégia para motivar os alunos. É divertido e ao mesmo tempo desafiador.

Os aprendizes reconhecem a possibilidade de aprender com jogos, pois os desafiam a pensar sobre as possibilidades do jogo, aliando a temática literária (uso de cartas mágicas) para promover o raciocínio e engajamento.

A questão 4 enfatiza as dificuldades enfrentadas pelos jogadores no começo dos embates:

Sujeito C: A parte mais difícil é entender a conta ou o cálculo matemático do ataque e defesa contra o valor da carta do outro jogador. Por exemplo, a carta da Cavalaria de Camelot tinha mil pontos de 
ataque e oitocentos pontos de defesa. Só se sabe a resposta se a combinação de valores entre soma e diminuição resultar maior para o vencedor.

Sujeito D: A mecânica do jogo é complexa no começo do jogo, mas conforme vai se familiarizando com a cartas e as regras o jogo vai ficando mais atrativo e fácil de entender.

Os primeiros passos com o jogo exigem a compreensão dos valores de cada carta e a jogabilidade dos personagens. Por exemplo, a carta "Merlin-O mago" tem um poder de defesa "médio" e ataque "baixo". Comparando a carta "Kilgara-O grande dragão" com a que tem poder de ataque "alto" e defesa "alto" (maior do que todas as outras do deck), pode ser anulada e ter a pontuação revertida para o jogador que conjurar (descartar) pela Carta Merlin, porque na regra do jogo o mago tem o poder de controlar os dragões.

Sobre a leitura de textos instrucionais em língua estrangeira e materna, os sujeitos relataram, a partir do item 6 da entrevista, que não tiveram dificuldades e que, quando surgia alguma dúvida, era pesquisada na internet ou sanada pelo moderador do jogo, no caso, o professor de inglês:

Sujeito A: A compreensão dos textos é uma forma de entrar no tema do jogo. As palavras mais difíceis ou desconhecidas são fáceis de se pesquisar em dicionários eletrônicos.

Sujeito B: Os textos das cartas poderiam dar mais detalhes sobre o jogo.

As regras do jogo são instruções básicas em inglês sobre a jogabilidade com as categorias de cartas inspiradas nos personagens das lendas e contos do Rei Arthur. Os alunos aprendem novas palavras a partir de consultas a dicionários online. 0 jogo, segundo sujeito B, apresenta algumas limitações. Como o Clash of Class é um protótipo de jogo recente, careceu de experimentações, sendo necessária uma maior testagem das cartas e regras do jogo. É comum em gêneros de jogos de cartas como esse que hajam as chamadas expansões e updates(atualizações). Existe a possibilidade de este estudo ser continuado, considerando os resultados das análises dos dados para a realização de ajustes.

No item 8 , os sujeitos forneceram informações sobre o modo como eles se sentiram diante dos desafios do jogo:

Sujeito A: 0 jogo, de certa maneira, estimula e tem que resolver a continha rapidamente. Caso contrário o oponente leva vantagem.

Sujeito D: 0 desafio motiva a pessoa a querer vencer o jogo. Tem que usar as cartas certas e ter um pouco de sorte. 
O jogo, de certo modo, atinge um dos propósitos que é o de manter os jogadores envolvidos. Percebe-se que o grau do desafio está além da sorte de obter uma carta com boa pontuação, mas também a exigência de lançar mão de estratégias e combinações de cartas para se fazer vencedor a cada embate. De acordo com os relatos, lidar com as operações matemáticas podem ser decisivas para se obter êxito no jogo.

A questão 9 indaga os sujeitos sobre os seus pontos de vista sobre 0 desenvolvimento de habilidades linguísticas e matemáticas:

Sujeito C: O jogo é divertido. Poder ser útil porque faz pensar para vencer.

Sujeito D: Nem sempre o jogo ensina. Pode ocorrer que para algumas pessoas esse tipo de jogo não seja interessante.

O uso jogos como recursos educativos pode não ser tão efetivo dependendo do público a que se destina. Segundo a afirmação do aprendiz "D", nem todas as pessoas compartilham dos mesmos gostos, podendo assim serem submetidas a atividades lúdicas que não thes chamam a atenção. 0 êxito sobre a aplicação de algum jogo, independentemente do gosto dos estudantes depende de um bom planejamento de aula que tenha o potencial de "convencimento", possibilitando a participação do estudante sem que o "force" a algo que possa o expor ao fracasso/derrota e frustrá-lo. A aprendizagem fundamentada em elementos de jogos, segundo Prensky (2001) pode ter um papel importante como recurso de aprendizagem que não é intrinsecamente motivador para qualquer pessoa, mas que precisa ser aprendido. Os jogos devem servir para tornar o mundo melhor para as pessoas, afirma McGonigal (2010). No caso do Clash of Class, busca-se valorizar o espírito de participação em uma estória épica, encarnando um rei como personagem que tenta conquistar novos territórios.

A última parte da entrevista buscou levantar informações sobre que elementos do Clash of Class são mais e menos interessantes para o contexto de aprendizagem:

Sujeito A: O jogo promove a integração entre as pessoas para jogar e se divertir. Ao mesmo tempo que o jogo pode ser uma atividade lúdica e prazerosa, dá para aprender.

Sujeito B: O desafio do jogo é o mais interessante porque não tem como prever um final. O jogo é interessante porque a dinâmica de colocar as cartas e quando aparece uma do tipo especial, mágica dá para reverter o resultado. 0 ponto ruim é entender as regras do jogo, quando e com qual carta usar para se defender de um ataque. 
Com base nos dados coletados e nos relatos dos alunos, observou-se que o desafio proposto no jogo é o que tornou a aprendizagem motivadora e divertida (GEE, 2009). A diversão referida pelos aprendizes é validado por Prenky (2001). Segundo o autor, boa parte de nossas vidas, 0 aprendizado se tornará verdadeiramente um aprendizado divertido. Notase que os sujeitos estavam engajados em superar os seus oponentes usando cálculos e operações matemáticas para computar os pontos de ataque e defesa de cada carta. Segundo Silva (2005), o ensino interdisciplinar com o uso de jogos é um recurso para o educador promover aulas mais divertidas e dinâmicas, podendo competir em igualdade de condições com os inúmeros recursos. Nesse sentido, o Clash of Class tem potencial para servir como um recurso adicional para as aulas de matemática e de língua inglesa. 0 jogo possui elementos de diversão como desafios épicos e imprevisibilidade de resultado (SHELL, 2008) dando mais "emoção" a cada descarte.

Os alunos tiveram uma boa compreensão das estratégias dos embates $e$ interpretaram as instruções em língua inglesa para regular a combatividade no jogo. Assim, as dinâmicas do jogo permitiram o desenvolvimento de suas habilidades matemáticas, além das estratégias de leitura e ampliação de seu vocabulário em inglês.

\section{Considerações Finais}

O objetivo deste trabalho foi investigar o engajamento dos estudantes em uma proposta colaborativa, visando desenvolver habilidades sociais, linguísticas e matemáticas de estudantes da educação básica. O professor de inglês foi mediador da atividade Clash of Class. Ele observou que os aprendizes aparentavam motivados e engajados durante as propostas lúdicas do jogo por conta da dinâmica dos desafios

A ideia central do projeto de desenvolvimento do Clash of Class consiste em expandir a proposta pedagógica para as escolas da rede de ensino público. Todos os materiais dos jogos serão disponibilizados gratuitamente, podendo ser confeccionadas com materiais recicláveis, por exemplo. Além disso, o jogo pode ser adaptado e/ou reeditado para se adequar e atender às propostas pedagógicas dos professores em suas respectivas escolas. 
Por fim, entendemos que o trabalho realizado no projeto e a integração do jogo como ferramenta auxiliar de ensino pode contribuir para aprimorar o processo educativo. Dessa forma, os jogadores não são apenas expectadores. Eles também são atores que propõem finais imprevisíveis para a sua boa aprendizagem.

\section{Referências}

BOGDAN, R. C.; BIKLEN, S. K. Plano de investigação. In: Investigação qualitativa em educação. Porto: Porto Editora, 1994. Parte II- p 81-109.

GEE, J. P. Bons videogames $e$ boa aprendizagem. (2009) Disponível em: <https://periodicos.ufsc.br/index.php/perspectiva/article/view/2175795X.2009v27nıpı67>. Acesso em: 14 set. 2017.

MCGONIGAL, J. Gaming can make a better world. (2010) Disponível em: <https://www.ted.com/talks/jane_mcgonigal_gaming_can_make_a_better_world>. Acesso em: 4 mar. 2018.

PRENSKY, M. The Digital Game-Based Learning Revolution. (2001) Disponível em: <http://www.marcprensky.com/writing/Prensky\%20-\%20Ch1-Digital\%20Game-Based\%20Learnin g.pdf>. Acesso em: 5 out. 2018

SCHELL, J. Art od Game Design: a book of lenses. EUA: Morgan Kaufmann, 2008.

SILVA, M. S. Clube de matemática: jogos educativos. 2 ed. Campinas, SP: Papirus, 2005.

YIN, R. K. Estudo de caso: planejamento e métodos. 2 ed. Porto Alegre: Bookman, 2001.

Data de submissão: 10/01/2018. Data de aprovação: 05/11/2018. 